\title{
La Evasión de la Ciudad en las Novelas de Roberto Arlt
}

La novela urbana, cuyo auge estamos presenciando hoy en toda América Latina, tuvo sus precursores en este continente, y sobre todo, en la Argentina, donde sin exagerar, se puede afirmar que nació urbana. El primer relato de importancia escrito en la Argentina, El matadero de Echeverría, ocurre en la ciudad y es el primer documento auténtico del Buenos Aires de entonces. Inclusive, la mejor novela romántica, Amalia de Mármol, tiene lugar en Buenos Aires, aunque sea una evocación nostálgica de la ciudad vista desde el destierro. La novela urbana reaparece con nuevo vigor en La gran aldea de Lucio V. López y con los naturalistas, Cambaceres, Argerich, Sicardi y Martel, quienes la enriquecen con nuevos personajes novelables.

Hay, pues, una tradición muy viva de novela urbana en la Argentina desde el siglo xix, que a principios de éste es continuada por Manuel Gálvez; y a fines de la década de los veinte, cuando los best sellers del momento eran las novelas de la tierra y las indigenistas, es Roberto Arlt (1900-1942), quien con sus novelas Los siete locos '(1929) y Los lanzallamats (1931), no sólo rompe con aquella tradición novelística sino que introduce la novela típica del siglo veinte, la novela de los contextos urbanos y, al hombre de las grandes concentraciones urbanas, donde la civilización y la mecanización han hecho la vida imposible. Es por demás curioso que sea Arlt, un hombre urbano él mismo, que vivió casi toda su vida en Buenos Aires, el que sueñe con la utopía clásica, de Horacio y de Fray Luis de León, con la vida del campo, fueta de la ciudad, "lejos del mundanal ruido". Los siete locos y Los lanzallamas, en más de un sentido son el menosprecio de corte y alabanza de aldea, corte que es ciudad, y aldea, que es campo virgen, no civilizado ni mecanizado. Sus personajes típicos son los de la clase media, el "hom. bre de Corrientes y Esmeralda", como lo llamó Raúl Scalabrini Ortiz, ${ }^{1}$ la

1 Raủl Scalabrini Ortiz, El bombre que está solo y espera (Buenos Aires: Editorial Reconquista, $7^{\mathrm{a}}$ ed., 1941). 
clase dominante en la vida de toda ciudad, los empleados, los comerciantes, los burócratas, los rufianes y las prostitutas, y digo rufianes y prostitutas, porque en Arlt estos marginales de la ciudad - como todos los personajes de Arlt-, son o han sido o tienden a ser clase media. Son los humillados, los angustiados, los psicópatas de la ciudad que querrán destruirla o huir.

Ante los males que Arit ha acumulado sobre la ciudad, "ciudad peste", "ciudad cáncer", "ciudad prisión", ciudad como "chaleco de fuerza", "ciudad cobarde", "ciudad bosque de ladrillo", etc. no les queda a sus personajes otro recurso que la fuga o la destrucción. Finga real de la ciudad al campo y fuga imaginaria por medio del sueño y la evasión; destrucción de toda la ciudad, una especie de suicidio colectivo o suicidio individual como último recurso. El protagonista de Los siete locos, Augusto Remo Erdosain, no puede aguantar más esa "ciudad negra":

...con graneros cilíndricos de cemento armado, vitrinas de cristales gruesos, $y$, aunque quiere detenerse, no puede. Se desmorona vertiginosamente hacia una supercivilización espantosa: ciudades tremendas en cuyas terrazas cae el polvo de las estrellas, y en cuyos subsuelos, triples redes de ferrocarriles subterráneos superpuestos arrastran una humanidad pálida hacia un infinito progreso de mecanismos inútiles. ${ }^{2}$

Ante esa ciudad supercivilizada donde se aburre todo el mundo no queda otro remedio que huir o suicidarse. No creo que sea por casualidad por lo que todos los personajes de Arlt eligen una u otra forma de evasión.

$Y$ no es solamente el novelista quien ha visto la imposibilidad de sobrevivir en la ciudad. Werner Hegemann (pseudónimo del urbanista alemán, Manfred Maria Ellis, 1881-1936), que en 1930 estudió los problemas urbanos de Buenos Aires, había llegado a las mismas conclusiones que Arlt, de que para corregir sus vicios de conformación y desarrollo no había sino una solución extrema subdividida en tres: "Un gran incendio, una gran revolución o un gran terremoto". ${ }^{3}$ Así como Hegemann habia dicho "que no es preciso amontonar a los bo.

2 Roberto Arlt, Los lanzallamas, en Novelas completas y cuentos, II (Buenos Aires: Fabril, 1963), pp. 33-34. De aquí en adelante citaremos por esta edición.

3. Von Werner Hegemann, "Als Städtebauer in Südamerika", en Stàdtebau, Vol. 16, 1932, pp. 141-148; 193-196 y 257-261. 
naerenses como ganado ante el matadero", ${ }_{4}$ así Erdosain, constantemente se referirá a la ciudad como "zona de angustia" que como "una nube de gas venenoso" penetra las murallas y atraviesa los edificios, donde se aglomeran los hombres como rebaños. ${ }^{5}$ Años más tarde, Ezequiel Martínez Estrada, en un artículo titulado "La cabeza del gigante", vuelve a reiterar que "Buenos Aires es una enfermedad mortal de la república", ${ }^{6}$ es decir, después de veinticinco años de publicada Radiografía de la pampa (1933) y La cabeza de Goliath (1940), el problema de la ciudad seguía tan vivo como antes, y al decir del ensayista argentino, la enfermedad de los tiempos de Arlt se había transformado en tumor.

Tal vez se pueda argïir que la solución dada por Arlt al problema de la ciudad -la fuga, la destrucción o el suicidio-es romántica y no resuelve nada, pues si es verdad que se está contra la maldad de las ciudades, con demasiada frecuencia se olvida que son males necesarios, imprescindibles para la subsistencia del género humano. ${ }^{7}$ No vamos a discutir la necesidad vital de las ciudades, pero tenemos que reconocer que cierto sector de la humanidad no puede resistir su presión y no tiene más remedio que suicidarse o huir. ${ }^{8}$ Se trata de no volverse loco, como ocurre con los personajes de Los siete locos. El ejemplo típico de esta actitud es Horacio Quiroga, quien literalmente se ahogaba en la ciudad y huyó a la selva de Misiones. Claro, los personajes de Quiroga son los desterrados de la ciudad y de su país, los inmigrantes fracasados y los varados en la vida - como lo fue el padre de Arlt-; en cambio, los personajes de Arlt son los esclavos de la ciudad, lo's que se sienten acorralados por los muros de ladrillo.

\section{La Fuga al CAMPo}

La primera, y aparentemente, la más fácil solución al problema de la ciudad es la fuga. Casi todos los personajes de Arlt piensan en la fuga de la ciudad aunque muy pocos la realizan. Silvio Astier, el protagonista de El juguete rabioso (1926), después de traicionar al Rengo, le dice al ingeniero que lo quiere recompensar: "Vea; yo quisiera

${ }^{4}$ Ibid.

5 Roberto Arlt, Los siete locos, en Novelas completas y cuentos, I, p. 161.

- Recogido póstumamente en Leer y escribir (México, Mortiz, 1969), p. 137.

7 José Enrique Miguens, "Un análisis del fenómeno", en Argentinat, 19.301960 (Buenos Aires: Sur, 1961), p. 335.

8 Las estadísticas han demostrado que las ciudades de mayor concentración tienen mayor porcentaje de suicidios que los pueblos o el campo. 
irme al Sur... al Neuquén...9 allá donde hay hielos y nubes... y grandes montañas... quisiera ver la montaña..."10 Erdosain también quiere irse "un tiempo afuera, estar en la montaña, descansar y estudiar". ${ }^{11}$ Astier y Erdosain quieren ser inventores -el sueño dorado del propio autor- lo que sólo puede realizarse por medio del estudio en Ia soledad del campo. Estanislao Balder, el protagonista de El amor brujo (1932), quiere comenzar una vida nueva fuera de la ciudad, cerca de las montañas. Es decir, los tres protagonistas de las novelas (son tres novelas con cuatro títulos las que escribe Arlt) reiteradamente hablan de la fuga de la ciudad. El narrador de Los siete locos, clarificando este deseo de su protagonista, comenta: "...él quiere escaparse de las prisiones de cemento, hierro y cristal.... Erdosain quiere escaparse de la civilización; dormir en el sol de la noche, que gira siniestro y silencioso al final de un viaje cuyos boletos vende la muerte". ${ }^{12}$ El deseo de la fuga es pues real, aunque el protagonista se resiste y se resistirá hasta el final, incluso cuando el Astrólogo le ofrece la última oportunidad de marcharse "muy lejos", Erdosain rehusa y el Astrólogo no insiste, porque ha comprendido que Erdosain "había ya trazado su destino"13 Los protagonistas de Arlt comprenden que el sufrimiento ha invadido toda la tierra, porque ya no queda un pedazo limpio del paso de los hombres. Sin embargo, no dejan de sentir "una nostalgia terrible de las llanuras con miniadas colinas", y su amargura crece al pensar que "está solo, en un siglo de máquinas de extraer raíces cúbicas y cinema parlante". ${ }^{14}$ Muchas veces Erdosain está a punto de irse al aserradero a la orilla del âgua $\mathrm{o}$ a la cordillera, pues el protagonista ha comprendido que "no es posible seguir así, no es posible", piensa al caminar por las calles de la ciudad del brazo de la Bizca, una chica de catorce años a la que compra a su madre y luego mata. $\mathrm{Y}$ la idea de la fuga persiste tentadora: "Y durante un instante piensa en fugar. Si se fuera muy lejos, a vivir ignorado, cerca de un río a cuya orilla hubiera un aserradero donde corrieran ratas grandes como perros". ${ }^{15}$

Ni Erdosain ni Balder realizan sus deseos de huir de la ciudad; son demasiado cobardes para lanzarse a la aventura, son víctimas de ella. Otros personajes, en cambio, están a punto de escapar de la ciudad, como Atturo Haffner, alias el Rufián Melancólico, el "cafishio" que

9 Al sudoeste de Buenos Aires, en la Patagonia.

in Roberto Art!, El juguete rabioso, en Novelas completas y cuentos, I, p. 156.

11 Lor siete locos, p. 232.

12 Lrs lanzallamas, p. 201.

1.) Ilid. p. 243.

14 thid., p. 156 .

15 Ibid., p. 186 . 
vive a costa de tres mujeres, quien claramente confiesa que "en esta ciudad se aburre todo el mundo". ${ }^{16}$ Haffner se pregunta "¿qué hago aquí en esta ciudad? Estoy aburrido. Mi vida no tiene objeto". Y a esta vida de la ciudad la llama "vida puerca" en oposición a la vida ideal del campo. Minutos después de haber tomado la decisión de irse de la ciudad, es asesinado por el hampa porteña.

El Buscador de Oro (uno de los miembros de la sociedad secreta encargado de organizar las colonias revolucionarias en el campo) comenta: "esos que no están cómodos en las ciudades no tienen derecho a molestar a los que la gozan. Para los descontentos e incómodos de las ciudades están la montaña, la llanura, la orilla de los grandes ríos".17 Es decir, para esos angustiados habitantes de las ciudades está el campo, la libertad, la pureza de la vida, la imaginación creadora. El ideal renacentista vuelve a darse en Arlt de una forma más concreta en los falsos pastores de Garcilaso y Montemayor. La ciudad moderna es una realidad monstruosa que los hombres del Renacimiento no habían imaginado. Por lo tanto la fuga de la ciudad es mucho más urgente que los artificios pastoriles de Arcadia:

Desafiando la soledad, los peligros, la tristeza, el sol, lo infinito de la llanura, uno se siente otro hombre... distinto del rebaño de esclavos que agoniza en la ciudad. ¿Sabe usted lo que es el proletario, anarquista, socialista, de nuestras ciudades? Un rebaño de cobardes. En vez de irse a romper el alma a la montaña y a los campos, prefieren las comodidades y los divertimientos a la heroica soledad del desierto. ¿Qué harían las fábricas, las casas de modas, los mil mecanismos parasitarios de la ciudad si los hombres se fueran al desierto... si cada uno de ellos levantara su tienda allá abajo ${ }^{18}$

16 Ibid., p. 42.

17 Los siete locos, p. 296.

18 Ibia. Hay un texto de Scalabrini Ortiz (op. cit., pp. 116-117) que confirma lo observado por Arlt. Dice el ensayista porteño: "Si a un porteño se le of rece partir para la Patagonia, en cuyas desolaciones llevará una vida retraída de cenobita y de donde volverá veinte años más tarde con un millón de pesos, o al año con cien mil 'morlacos', el porteño, sin aturdirse ante el cabrioleo de las sumas, balancea las pérdidas de vida y las ganancias de oro del ofrecimiento. Un millón es plata, pero veinte años son casi la mitad o el tercio, por lo menos, de la vida, durante los cuales estará como impedido, será un baldado de la civilización: no tendrá amigos, novias, calles que recorrer, cinematógrafos... De pronto la ciudad se embellece, la ciudad se engalana ante esa probabilidad de destierro y el porteño dice: 'No, che, no, yo no estoy hecho para las fajinas del campo". 
Difícilmente se puede encontrar en la literatura del siglo veinte, en la novela urbana, una apología tan completa del campo como en las de Arlt. Este hecho que pasó casi inadvertido hasta el presente es uno de los puntos más importantes de la temática arltiana. Temática tan antigua como la literatura misma, y cuyo clásico ejemplo está en el contraste que se puede establecer entre las dos partes del Quijote. ${ }^{19} \mathrm{La}$ idea del Buscador de Oro es obvia: si todos los hombres fueran lo suficientemente valientes como para abandonar la ciudad, no sólo encontrarían un des. tino más digno sino que causarían el derrumbe del sistema social imperante.

El Astrólogo afirma una y otra vez que el futuro del hombre, del hombre nuevo, sólo puede darse en el campo: "Yo quiero que sea futuro. Futuro en campo verde, no en ciudad de ladrillo. Que todos los hombres tengan un rectángulo de campo verde, que adoren con alegría a un dios creador del cielo y de la tierra". ${ }^{20}$ Porque sólo el campo puede devolver al hombre su dignidad y su fuerza, echada a perder por los comerciantes y los políticos. El plan mismo de la nueva sociedad organizada por el Astrólogo "sólo se puede llevar a cabo en el campo"21 nos dice él mismo. Parecidos testimonios harán los otros personajes de la novela, como Ergueta, el loco cuerdo de la novela, "no, no es en las calles dondel están las fuerzas del mundo; es en los campos"; ${ }^{22}$ y el Buscador de Oro, citado antes, dirá, "todo es grande... enorme... allá... allá se salvan las almas que enfermó la civilización" ${ }^{23}$ La idea de que el campo es la salud del cuerpo y del alma es tan reiterativa que uno se pregunta, ¿cómo el autor de estas obras resistió los 42 años de su vida en la ciudad?

Como la decisión de los protagonistas, Erdosain y Balder, y de los demás personajes, de fugarse de la ciudad casi nunca se materializa, por aquello de que son hombres cobardes de la ciudad, para quienes es más cómodo soñar que actuar, se evaden por otros medios, menos radicales, como el sueño. Tanto Erdosain como Balder son soñadores, para quienes el sueño reemplaza a la vida, y quienes prefieren torturarse ante la imposibilidad de encontrar salida a su angustia de la ciudad a dar el paso libertador. El hábito de refugiarse en el sueño no es necesariamente pereza o cobardía, aunque muchas veces está muy cerca de serlo, sino

19 T.a primera parte toda en el campo, en la libertad, y la segunda, casi toda citcunscrita a la casa. al palacio. a la cindad.

20 Los lanzallamas, p. 27 . Obsérvese que to dice un ateo, comunista y anarquista.

21. Ibid, p. 86 .

22 lbid, p. 220.

23 Los sieta locos, p. 295. 
un escape hacia la itrealidad. Erdosain y Balder se impacientan ante su inercia y nulidad, ante la máquina social que los tiene atornillados allí para siempre: "es inútil cuanto haga -dice Erdosain-igual que las fieras enjauladas, va y viene por su cubil frente a la indestructible reja de su incoherencia. Necesita obrar, mas no sabe en qué dirección". ${ }^{2.4}$ Ante la imposibilidad de obrar, el protagonista se contenta con lamentarse y soñar en su desdicha:

Piensa que si tuviera la suerte de encontrarse en el centro de una rueda formada por hombres desdichados, en el pastizal de una llanura o en el sombrío declive de una montaña, él les contaría su tragedia. Soplaría el viento doblando los espinos, pero él hablaría sin reparar en las estrellas que empezaban a ser visibles en lo negro. Está seguro que aquel círculo de vagabundos comprendería su desgracia, pero allí, en el corazón de una ciudad, en una pieza perfectamente cúbica y sometida a disposiciones del digesto municipal, es absurdo pensar en una confesión. ${ }^{25}$

Pero Erdosain, que tanto sueña con irse al campo, no tiene fuerzas para hacerlo. Sabe que en la llanura, en la montaña podría encontrar la paz, podría renovarse y vivir, pero nunca pasa de pensar "en un mundo más nuevo, con grandes caminos en los bosques, y donde el hedor de las fieras fuera más incomparablemente dulce que la horrible presencia del hombre". ${ }^{26}$ Hay una voluntad ajena a la suya, "un chaleco de fuerza", la voluntad de la ciudad que no lo dejará escapar. Erdosain escucha a su conciencia que le susurra que se vaya "lejos, lejos", "más allá de las ciudades... al otro lado de las ciudades, y de las curvas de los ríos y de las chimeneas de las fábricas". ${ }^{27}$ Pero la fuga no se realiza porque soñar es mejor que actuar, y "perder un sueño es casi como perder una fortuna. ¿Qué digo? Es peor" dice Erdosain, y se queda soñando. ${ }^{28}$

Balder, cömo Erdosain, no pasa de soñar su vida en el campo ("vertiginosamente por la imaginación de Balder cruzan montañas, nieve, casas de techo inclinado" $)^{29}$ donde comenzaría una vida nueva, que para el protagonista de El amor brujo significa abandonar todo su pasado, su mujer e hijo, para casarse con Irene, a la que cree virgen, co-

24 Los lanzallamas, p. 51.

25 Ibid.

26 Los siete locos, p. 254. Es el mundo del paraiso perdido de Rousseau, $y$ de Carpentier en Los pasos perdidos.

27 Los lanzallamas, p. 58.

28 Los siete locos, p. 234. Para Machado de Assis, soñar era mejor que vivir.

29 Roberto Arlt, El amor brijo, en Novelas completas y cuentos, III, p. 114. 
mo el campo. Al fracasar su sueño de la virginidad de Irene, la segunda parte de su sueño se derrumba por sí sola, y Balder se reconcilia con su mujer y su hijo y su ciudad.

La fuga de la ciudad es una obsesión en las obras de Arlt. La felicidad del hombre, de la humanidad, depende de cómo resuelva el problema de la ciudad, lugar antinatural para el hombre. El hombre no puede vivir separado de su tierra, tiene que tener sus raíces y nutrirse de la tierra; volver, pues, a la tierra es el mensaje de sus novelas. Mensaje implícito, expresado por el desvivirse de sus personajes. Hay que reconocer el talento del autor de haber podido crear personajes tan complejos, que, aunque se percatan de que la ciudad los destruye, se obstinan en permanecer en ella hasta el final y que, como Erdosain, buscan otras soluciones, más radicales y definitivas.

\section{La Destrucción de la Ciudad}

La segunda solución of recida por los personajes de la narrativa de Arlt y ya señalada por Hawthorne (The Marble Faun) y por casi todos los grandes novelistas del siglo XIX, es que hay que destruir la ciudad por medio del fuego, de un terremoto o de una revolución. Como para una destrucción efectiva no bastan los esfuerzos individuales, se necesita un grupo organizado, secreto y disciplinado compuesto por una minoría de especialistas y locos, que en las novelas de Dostoievski (Demonios) y en la novela capital de Arlt se llama la sociedad secreta. El novelista porteño tiene una manía por organizar clubes, sociedades, órdenes caballerescas, vestigios de sus lecturas rocambolescas y picarescas. Esto ya fue señalado por David Maldavsky: "Si en apariencia la gente realiza grupos por alcanzar ciertos objetivos creadores y al mismo tiempo 'trabaja' así al grupo mismo, lo va creando, en la mítica de Arlt se invierten los términos, y los personajes que unen para destruir, y tanto esto no ocurre que el grupo se autodestruye". ${ }^{30}$ Lo importante en este embrollado párrafo de Maldavsky, es que los personajes se unen para destruir o autodestruirse. Desde el primer episodio de El juguete rabioso hasta la última línea de Los lanzallamas y algunas páginas de El amor brujo, la palabra clave es "destrucción". Desde el momento en que Silvio se junta con otros chicos del barrio, empieza a planear la muerte y la destrucción de sus semejantes: envenenar balas y fabricar bombas para

30 David Maldavsky, Las crisis en la narativa do Roberto Awt (Buenos Aires: Escuela, 1968), p. 22. 
mandarlas por correo a los jueces. Silvio no sólo quiere ser inventor, asombrar el mundo, tener fortuna y hermosas mujeres, sino también destruir y dañar el mundo, "porque el mundo no es sólo cruel sino también estúpido, no sabe quiénes lo componen, y destruye a sus mejores integrantes", dice Noe Jitrik. ${ }^{31}$ Silvio confiesa que la convicción de haber creado un cañón que puede matar lo "enajenaba de alegria". Y cuando está en Ia Escuela Militar de Aviación, Silvio le comunica a su superior un proyecto de mortero que permita "destruir mayor cantidad de hombres". ${ }^{2}$

Lo que en El Juguete rabioso sólo está en esbozo, cobra proporciones escandalosas en Los siete locos y Los lanzallamas, donde se proyecta en cuestión de horas el exterminio de toda la ciudad. El joven tebelde de la primera novela se ha vuelto un hombre maduro y desesperado, que se ha asociado con otros tan desilusionados como él, para planear en serio el fin apocalíptico de la ciudad.

El proyecto de la sociedad secreta (el "quinquevirato" de Dostoievski) tiene un fin muy concreto: la aniquilación de los habitantes de la ciudad por medio de gases, el sueño dorado de Erdosain, miembro de la sociedad, "esto hay que barrerlo con cortinas de gas", dice repetidamente. La destrucción de Buenos Aires significa también la destrucción de la nación, pues como dijo Martínez Estrada, "Buenos Aires es la ciudad-nación". ${ }^{33}$ Limpiar la ciudad es limpiar a todo el país de comerciantes, empleados, de explotadores y explotados. Porque lo que no se puede cambiar hay que destruirlo, removiendo los cimientos de la sociedad. Erdosain, incluso, llega a soñar con la destrucción total, haciendo "saltar en cascajos. las ciudades de portland, como si las soliviantaran volcanes de trititotolueno". ${ }^{34}$

El único proyecto de la sociedad secreta que pasa del primer estado de mera "conversación" es un manual para la instalación de una fábrica de gas, compuesto por Erdosain. El autor llega, para hacerlo más realista, a incluir el manual en el cuerpo de la novela con dibujos y gráficas. Meintras Erdosain trabaja en su proyecto, tiene dos visiones o sueños: ${ }^{35}$ un recuerdo de su infancia - que precisamente es un epi-

31 Noé Jitrik, Escritores argentinos: Dependencia o libertad (Buenos Aires: Candi1, 1967), F. 87.

$32 \mathrm{El}$ juguete rabioso, p. 105.

33 Ezequiel Martinez Estrada, Radiografia de la pampa (Buenos Aires: Losada, 6a ed. 1968), p. 194.

34 Los siete locos, p. 373.

Estas visiones o sueños podrían servir para un interesado en los probiemas psicológicos de las novclas. 
sodio de juegos destructivos - y una visita "enigmática". ${ }^{36}$ El primer episodio prueba que la manía destructora del protagonista procede de su más tierna juventud y que la edad madura sólo la acentúa y magnifica. El segundo, en cambio, es simbólico y ambiguo. En primer lugar, Erdosain trabaja en un proyecto concreto, una fábrica de gas pestifero que ha de barrer a los habitantes de la ciudad sin discriminación. "Jamás ha pasado la humanidad por una crisis de odio como ahora", ${ }^{37}$ dice el protagonista; por lo tanto ha llegado la hora, y a todos los ha de cubrir "la nube de gas verdulento". En segundo lugar, el "enigmático" visitante hace una crítica feroz de aquellos "honrados padres de familia" que han inventado esos gases infernales". ${ }^{38}$ Es como si el autor quisiera detener a su protagonista, advertirlo del peligro y de la barbaridad que hace, y por medio de él, a la humanidad que todavía estaba viviendo los vestigios de los gaseados de la primera guerra mundial. El enigmático visitante cuenta algunos casos presenciados en las trincheras para hacer más dramática su súplica. Erdosain termina llorando y llama "padre" al visitante, ${ }^{39}$ pero no por eso abandona su proyecto. Así como destruía las fortalezas de barro asi quiere destruir la ciudad de veras. $Y$ se lo dice el visitante: "Cuando eras chiquito jugabas al inocente juego feroz de bombardear fortalezas. Te has hecho hombre y querés cambiar el juego de las fortalezas que bombardeabas en la soledad por el juego de las fábricas de gas. ¿Hasta cuándo seguirás jugando, criatura?" 40

No sin remordimientos, Erdosain quería destruir la ciudad. Siempre queda un momento de duda, de vacilación que termina en la ambigüedad. Por un lado está su instinto de destrucción que se manifiesta desde la infancia, y por otro, un instinto de preservación, pues esa destrucción en definitiva es su propia aniquilación. Cuando Erdosain piensa en el asesinato de Barsut (primo de su mujer, delator de los robos del protagonista a la compañía en que trabaja y causante de su desgracia matrimonial), hace el siguiente soliloquio: "Si ahora viniera un dios y me preguntara: ¿Quetrés tener fuerza para destruir a la humanidad? ¿Yo la destruiría? ¿La destruiría yo? No, no la destruiría. Porque el poder

${ }^{36}$ El protagonista cree que alguien ha entrado en su cuarto con el rostro protegido por una máscara contra gases, un vivo reproche contra el plan del protagonista.

37 Los lanzallamas, p. 166.

.88 "Los químicos son hombres serios que contraen enlace muy jóxenes y tienen hijos a quienes les enseñan a adorar a la patria homicida" dice Erdosain. Ibid., p. 169.

${ }_{39}$ Es la única vez que el padre, aunque simbólicamente muerto, aparece con cariño en las novelas y cuentos de Arlt.

40 Los lanzallamas, p. 171. 
hacerlo le quitaría interés al asunto".11 Es la imposibilidad de su misión la que da acicate a sus sueños locos. En el fondo, Erdosain no quiere, como dice el Astrólogo, sino "desangustiarse", y sueña horrores con el mismo placer con que Silvio Astier soñaba con cañones que pudieran matar más hombres o el niño Erdosain destruyendo fortalezas de barro:

Cuando amontona el desastre cotidiano de un millón ochocientos mil habitantes que tiene la ciudad Erdosain se dice, como el hombre que sale de una clínica y acaba de constatar el éxito de una innovación quirúrgica. -Tiene tazón el Astrólogo. Esto hay que barrerlo con cortinas de gas, aunque sea inútil, aunque nos despedacen a "gomazos" en el Departamento. Su corazón se dilata como un cono en el corazón de la selva. Piensa que los profetas tenían razón cuando hacían caer sobre las ciudades agotadas por la inmundicia sus hipotéticas lluvias de fuego entre hedores de ácido sulfúrico. ${ }^{42}$

La ciudad es obviamente Buenos Aires (que precisamente tenía en aquel entonces ese número de habitantes), cuyo monstruoso crecimiento, sin paralelo en el Hemisferio Austral, hace pensar al protagonista en las Nínives bíblicas, condenadas a la destrucción; idea que Arlt, muy oportunamente, aplica a los tiempos modernos, cuando el hombre sí es capaz de hacer caer lluvia, no ya hipotética, sino muy real, de gases químicos inventados por honrados padres de familia. $\mathrm{Y}$ como si el gas no bastara, un poco más adelante, Erdosain dice que "quisiera estar acurrucado junto al tope de una ametralladora. Barrería en abanico la ciudad. Caerian hombres, mujeres, niños".

La furia endemoniada de Erdosain contra la ciudad nada tiéne que ver con la fría, calculada y cínica del Astrólogo, porque la destrucción de la ciudad es, en cierto modo, su propia destrucción. Es el desesperado suicida a quien no le importa arrastrar tras sí a toda la humanidad. Es el caso psicopático de un desesperado, de un angustiado; es la venganza de un humillado por la sociedad burguesa. Nadie se salva de la destrucción imaginada por Erdosain, ni los arrabales con "esas hijas de obreros, anémicas y tuberculosas, cuya juventud se desploma como un afeite bajo la lluvia"; ${ }^{3}$ ni los empleados de la ciudad, extenuados por

\footnotetext{
41. Los siete locos, p. 222.

42 Les lanzallamas, p. 190.

43 Ibid., p. 188.
} 
"la inmundicia cotidiana"; ni el Barrio Norte "con sus criados en las puertas de los garajes conversando de la grandeza de sus amos", ${ }^{44}$ ni los comerciantes "saliendo como vizcachas asustadas de sus madrigueras", al decir del Buscador de Oro ${ }^{45}$ Nosotros limpiaremos "de inmun. dicias el planeta con una ametralladora" fulminan los miembros de la sociedad secreta.

Si para Erdosain la destrucción de la ciudad es casi un asunto personal, para el Astrólogo es sólo una parte de su plan de la destrucción total para dominar el mundo, comenzando por los once millones de argentinos (población de la Argentina de 1930). "Este es un país de bestias", dice, "hay que fusilar". En un instante de verdadera locura, el Astrólogo mantiene un raro soliloquio, en el cual define sus ideas monstruosas:

El movimiento revolucionario estallará a la misma hora en todos los pueblos de la República. Asaltaremos a los cuarteles. Comenzaremos por fusilar a todos los que puedan alborotar un poco. En la capital se lanzarán días antes algunos kilogramos de tifus exantemático y de peste bubónica. ${ }^{46}$

El lector podria dudar del equilibrio mental de estos personajes, quienes en un momento de franqueza confiesan que "todo esto es una locura posible", es decir, el Astrólogo no es tan loco como para no ver la locura de su locura, que, sin embargo, gracias a los "honrados padres de familia", es posible, "con diez hombres por pueblo y la Argentina es nuestra", dice. No es menos explícito cuando habla con Barsut, a quien le dice (después de haberlo tenido en cautiverio, extorsionado el dinero y simulado su muerte ante Erdosain): "No descansaré hasta que no haya montado una fábrica de gases. Quiero permitirme el lujo de ver caer la gente por la calle, como caen las langostas". ${ }^{47}$ Aunque el Astrólogo es el primero en reconocer lo disparatado de su plan, no cejará hasta el final, y sólo espera a que Erdosain le entregue el cuaderno con las instrucciones para montar una fábrica de gases, para, simbólicamente, desaparecer.

La destrucción de la ciudad también está en la visión de Ergueta (quien se ha vuelto loco jugando a la ruleta y casándose con una prostituta). Este, ya casi al final de la novela, cuando ya ninguno de los

44 Ibid., p. 207.

45 Los siete locos, p. 293.

46 Ibid., p. 359.

47 Los lanzallamas, p. 67. 
planes de la sociedad secreta se pueden llevar a cabo, tiene un sueño simbólico, tomado del Apocalipsis y aplicado específicamente a Buenos Aires:

Yo me encontraba en la azotea de la casa de gobierno, en compañía de un ángel amarillo. Este detalle es importante, porque el amarillo es manifestación de peste, guerra, desolación y hambre. Sin embargo, a pesar de encontrarme en la azotea de un edificio tan alto, los techos de las casas no eran visibles. La ciudad íntegra estaba cubierta de agua azul. El agua no se movía, sino que estaba quieta hasta el horizonte. ${ }^{48}$

La visión de Ergueta refuerza con medios sobrenaturales la idea general de los personajes, universalizando el problema, porque "han llegado de los tiempos cruentos", dice el farmacéutico citando la Biblia, no sólo para Buenos Aires y para el hombre que vive en la ciudad, sino para toda la humanidad.

El contrapunto que se puede establecer entre los planes concretos del Astrólogo y las profecías del loco Ergueta es una curiosa combinación de dos locuras, que en definitiva es el estado "normal" del hombre. "Lo que llamamos locura es la descostumbre del pensamiento de los otros", dice el Astrólogo, ${ }^{49}$ y podríamos agregar que no sólo de los pensamientos, sino también de los actos. La segunda guerra mundial y todo lo que siguió a ella hubiera parecido locura "profetizarlo"; sin embargo, después de consumados los hechos históricos, nos hemos acostumbrado a vivir con esa locura sin que nos cause mayor extrañeza. Los planes y las profecias de los personajes arltianos no son locuras que no puedan ocurrir después de todo. ${ }^{50}$

\section{El Suicidio como Solución Extrema \\ al Problema Urbano.}

El suicidio, intentado o cometido, ocupa gran parte de las obras arltianas. Y' aparece en El juguete rabioso, pero es en Los siete locos y Los lanzallamas donde no sólo el protagonista se quita la vida sino que

48 Ibid., p. 214.

49 Los siete locos, p. 377.

50 ¿Qué es Hiroshima sino la destrucción de la ciudad planeada por Erdosain? ¿Qué son las cámatas de gas hitlerianas y los campos de concentración soviéticos sino la explotación de los hombres soñada por el Astrólogo? 
casi todos los personajes de una u otra manera han intentado suicidarse. Sólo en El amor brujo no hay crímenes ni suicidios, aunque el protagonista demuestra interés por el problema del suicidio como una forma de expiación. Con cierta frecuencia, sin embargo, piensa en el suicidio como una solución a su angustia amorosa, "no sé si a esa mujer no tendré que matarla y matarme sobre ella", dice refiriéndose a Irene..$^{51}$

El suicidio es un fenómeno bastante común en Buenos Aires (y en cualquier gran ciudad). No creo que sea coincidencia que en el término de unos pocos años cuatro grandes figuras rioplatenses hayan cometido este acto desesperado: Horacio Quiroga (1937), Leopoldo Lugones (1938). Alfonsina Storni (1938) y Lisandro de la Torre (1939), y creo que si buscáramos en las estadísticas encontraríamos muchos más. En cada caso particular siempre daremos con un motivo especial para el suicidio: Quiroga, por ejemplo, se quitó la vida por tener una enfermedad incurable, lo mismo fue la Storni; Lugones y de la Torre, por haberse desilusionado de la vida política, etc., pero en todos ellos hay algo de esta falta de sentido en la vida que la hace inútil y absurda.

Los personajes arltianos llegarán a la misma conclusión. Silvio, ante la terrible realidad de haber sido expulsado de la Escuela Militar, su última oportunidad para alcanzar un futuro decente, ante la imposibilidad de escaparse de la ciudad con esas "calles de sombra formadas por los altos muros de los galpones", llega a la inevitable conclusión: "es inútil, tengo que matarme". Esta certidumbre en un chico de 16 años es la expresión última de su fracaso, debida no tanto a su propia incapacidad como a la impuesta por las circunstancias exteriores, por la sociedad que se niega a darle la oportunidad de ganarse la vida decentemente.

Otra cosa es Erdosain. Este tiene muchas posibilidades a su alcance. Puede aceptar el status quo y llevar una vida mediocre como tantos millones de empleados de la ciudad; puede huir a la montaña; puede destruir la ciudad - por lo menos intentarlo-, pero al final lo rechaza todo, como si sintiera la urgencia de acabar de una vez; "estoy perdido - dice-. Es mejor que me mate. Que le haga ese favor a mi alma". ${ }^{52}$ Hay que irse, pero ¿adónde? "Todas las costas del mundo están ocupadas por hombres feroces que con auxilio de cañones y ametralladoras instalan fábricas y queman vivos a pobres indígenas que se

51 El amor brujo, p. 127. Este deseo de Balder fue realizado por el matido de la poetisa Delmira Agustini, quien la mató y luego se quitó la vida en 1914. Es posible que Arlt tuviera presente este episodio histórico al escribir su novela. 52 Los lanzallamas, p. 59. 
resisten a sus latrocinios. ¿Irse! ¿Sabés lo que hay que hacer para irse? ...Matarse". ${ }^{3}$ La idea de la solución extrema va surgiendo cada vez con más clatidad. Todos los interminables soliloquios de Erdosain terminan en la certidumbre del suicidio: "Tiene la sensación de que "hay algo en él' que se aproxima insensiblemente al drama final", ${ }^{54}$ que no puede ser otro que la muerte, que después de la miserable vida que ha llevado no resulta tan terrible, "es un descanso amoroso, tierno, mullido".

Todos los personajes de Arlt están empeñados en una desesperada búsqueda del sentido de la vida. La vida de la ciudad carece de sentido porque es una vida supercivilizada y supermecanizada $\mathrm{y}$, ¿para qué queremos una vida así? Il Astrólogo lo confirma explícitamente: "nadie tendrá interés en conservar una existencia de carácter mecánico, porque la ciencia ha cercenado toda $f e$. $Y$ en el momento en que se produzca tal fenómeno, reaparecerá sobre la tierra una peste incurable... la peste del suicidio". ${ }^{55}$ Trece años después, Albert Camus escribirá algo muy semejante, en su Calígula: "Perder la vida es poca cosa y no me faltará el valor cuando sea necesario. Pero ver disiparse el sentido de esta vida, desaparecer nuestra razón de existir, eso es insoportable. No puede vivirse sin razón". ${ }^{56}$ 'Tanto Camus como Arlt se separan de la mentalidad del siglo XIX, como la de Dostoievski, para quien "La vida es hermosa hasta en la desgracia; siempre es bueno vivir, sea como sea". ${ }^{57}$ Los protagonistas de Arlt también dirán que la vida es linda, pero se preguntarán " $¿ \ldots y$ para vivir hay que sufrir tanto...?". ${ }^{58}$ Es decir, para Arlt, la vida setía hermosa, si el hombre no la hubiera ensuciado tanto que la hiciera invivible:

- ¿Vale, en realidad, la pena el trabajo de vivir? Uno, todos los días hace lo mismo, dice las mismas mentiras y las idénticas verdades; aburre a unos y distrae a otros, molesta a algunos y se hace odioso a varios, ¿vale la pæna de vivir? ¿Para qué?... Hasta llega a pensar: "podría uno meterse un balazo en los sesos". La humanidad no perdería gran cosa ni uno tampoco sufriría una pérdida irreparable. Y se pregunta por cienmilésima vez: "¿vale la pena

\footnotetext{
53 Ibid., p. 175.

54 Ibid,, p. 185.

55 Los siete locos, p. 267.

56 Albert Camus, Calignla, en Obras Completas, I (Madrid: Aguilar, 1959), p. 741 .

${ }_{57}$ Fiodor M. Dostoievski, Memorias del subsuelo, en Obras Completas, I (Madrid: Aguilar, 6a ed. 1957), p. 1516.

${ }_{58} \mathrm{El}$ juguete rabioso, p. 74.
} 
vivir así, o no vale la pena? La neblina se vuelve más espesa. Las campanas de los tranvías resuenan más alarmantes; los hombres van $y$ vienen, $y$ en realidad, moritse es casi como vivir. Con la diferencia, claro está, que cuando uno está muerto no debe aburrirse tanto. ${ }^{59}$

El texto del Aguafuerte p.orteña, que - dicho sea de paso- no se diferencia mucho de su estilo novelístico, repite la pregunta que atormenta a Erdosain. Y así como en las novelas el autor no encuentra una respuesta satisfactoria a su angustiosa pregunta, tampoco en su columna periodística acierta con una solución diferente de aquella de que "muerto no debe aburrirse tanto".

La obsesión del autor es la búsqueda de un sentido en la vida que se resume en la búsqueda de la felicidad. Arlt, angustiosamente, constata que el hombre civilizado no es feliz, que nunca lo ha sido. Erdosain es el personaje que mejor sabe esta verdad y se angustia: "ni rey ni prisionero, ni en el orgullo ni en la máxima humillación encuentra la felicidad", dice el narrador. Erdosain se tevuelve en maldiciones contra el "Dios canalla" que nos ha puesto esta necesidad en las conciencias y piensa que todos, incluso el vil comerciante y el miserable empleado, no son felices. Todos los personajes encarnan la angustiosa pregunta del autor: cómo ser felices. La conclusión es obvia: la vida no tiene sentido porque el hombre es incapaz de encontrar la felicidad y no es capaz de ser feliz porque la vida no tiene sentido. ${ }^{60}$

Si la vida no tiene sentido, el colofón sólo puede ser una solución extrema, el suicidio colectivo o el suicidio individual. Hay una conexión entre la destrucción de la ciudad planeada por la sociedad secreta y el asesinato y el suicidio. Como "la vida de un hombre no tenía ningún valor" piensa el Astrólogo, fusilar a millones, si no es un acto meritorio en sí, tampoco tiene gran importancia. Para los comunistas de la sociedad secreta la muerte de veinte millones de rusos no tiene ninguna importancia si los sobrevivientes han dado con el sentido de la vida. De ahí que Erdosain repita constantemente la frase de Lenin: "¡Qué diablo de revolución es ésta si no fusilamos a nadie!" La diagnosis del Astrólogo de que una humanidad que ha perdido su sentido de la vida

59 Roberto Arlt, Cronicón de si mismo (Aguafuertes porteñas) (Buenos Aires: Edicom, 1969), pp. 121-122.

${ }^{60}$ Arlt confiesa en una entrevista (La Literatura Argentina, agosto de 1929) su preocupación fundamental:. "Que soy un individuo inquieto y angustiado por este permanente problema: de qué modo debe vivir el hombre para ser feliz, o mejor dicho, de qué modo debía vivir yo para set complețamente dichoso". 
terminará en el suicidio justifica su plan de destrucción de las ciudades, porque los mismos hombres se preguntarán ¿para qué queremos una vida así? Y el Astrólogo pasa a describir el suicidio como la peste del siglo, invadiendo las ciudades: "¿Se imagina usted un mundo de gentes furiosas, de cráneo seco, moviéndose en los subtertáneos de las gigantescas ciudades $\mathrm{y}$ aullando a las paredes de cemento armado? ... ¿Y - las muchachitas y las escolares organizando sociedades secretas para dedicarse al sport del suicidio? ¿Y los hombres negándose a engendrar hijos... ?". ${ }^{61}$

Estas ideas suicidas son ejemplificadas por el autor en sus personajes. Aunque de todos los personajes de Los siete locos, sólo Erdosain lleva a cabo su largamente madurado suicidio, casi todos los demás, en una u otra forma, también lo han intentado. Hasta el Astrólogo, quien se cree destinado a fines más altos, confiesa haber pensado en el suicidio des. pués del accidente que lo dejó castrado.

Erdosain, el más consecuente con la tradición y la moral de su tiempo, repite constantemente que debe matarse. El autor, en una nota, pone la confesión del protagonista en primera persona (como si se le hubiera olvidado integrarla en el texto de la novela o se le hubiera ocurrido más tarde o quisiera hacerla destacar), donde claramente explica su posición.sobre el asunto:

Yo creía que el alma me había sido dada para gozar de las bellezas del mundo... cuando fui pequeño, creía siempre que la vida reservaba para mi un acontecimiento sublime y hermoso. Pero a medida que examinaba la vida de los otros hombres, descubrí que vivían aburridos, como si habitaran en un país siempre lluvioso, donde los rayos de la lluvia les dejaran en el fondo de las pupilas tabiques de agua que les deformaban la visión de las cosas. Y comprendí que las almas se movían en la tierra como los peces prisioneros en un acuario. Al otro lado de los verdinosos muros de vidrio estaba la hermosa vida cantante y altísima, donde todo sería distinto, fuerte y múltiple, y donde los seres nuevos de una creación más perfecta, con sus bellos cuerpos saltarian en una atmósfera elástica. Entonces me decía: es inútil, tengo que escaparme de la tierra. ${ }^{62}$

Escape que sólo puede tener un significado: el suicidio. Aquí Erdosain aparece como un romántico idealista que ha pasado por distin-

61 Lns siete locos, p. 267.

62 Ibid, p. 238, en nota. 
tas etapas buscando el sentido de su vida, en si mismo y en los demás, dentro y fuera del acuario (metáfora que Cortázar consagraría en su cuento "Axolotl"), para descubrir que todos vivían aburridos, prisioneros de la tierra, cuya libertad sólo se lograba con la muerte. Irse de esta tierra no puede ser otra cosa que morir, y ya que hemos de morir de todos modos, ¿por qué no hacer un favor a nuestra alma y hacerlo cuanto antes? Y después de repasar la vida de "tres mil millones de hombres y en el corazón de una ciudad", Erdosain se pregunta: "¿qué debe hacerse para terminar con semejante infierno?". 63 . Al evocar la vida miserable de tantos hogares, concluye: "Esa es la vida. ¿Pero es posible que ésa sea la vida? $Y$ sin embargo, ésa es la vida. La vida. La vviiiddaaa.... ¿De qué modo dar el gran salto?". ${ }^{61}$ Su vida fue echada a perder desde muy temprano, por su padre, por sus maestros, por sus amigos y por la "puerca civilización" que lo ha magullado y lo ha roto internamente. Erdosain sabe que su vida carece de valor; "esa sensación es evidente en su entendimiento - explica el narrador-, pero hay otras vidas, millones de vidas que dan pequeños grititos despertando al sol", y entonces se dice "que estas pequeñas vidas son las que se necesita salvar". ${ }^{65}$ Pero, ¿cómo? Un hombre que ha llegado a la conclusión de que su vida no tiene sentido, ¿cómo puede salvar a los demás? Erdosain cree que ayudando al Astrólogo, pero en su intimidad ya no cree ni en esa posibilidad.

$Y$ entonces decide recurrir al último experimento: el crimen. Erdosain confiesa que sintió terror y un espantoso miedo al descubrir que su vida no tenía sentido, y que al fin lo había encontrado: "he condenado a muerte a un hombre". Arlt hace una réplica de la situación dostoievskiana de Kirilov (en Demonios), y dice que "ciertas determinaciones (el asesinato) lo convierten a uno en un dios". ${ }^{66}$ "Desde hace mucho tiempo que estoy resuelto a matarme - confiesa el protagonista a Hipólita - ... Si supiera lo hermoso y grande que me siento!". Pero si el protagonista ha resuelto matarse, ¿para qué el asesinato de Barsut?, el primero de una serie de tres. Erdosain explica que "todavía no he llegado al fondo de mí mismo... pero el crimen es mi última esperanza". Y es en este lugar donde Erdosain confiesa el pecado que lo tiene angustiado (el escándalo de que es víctima una niña de ocho años) y explica: "El pecado es un acto por el cual el hombre rompe el débil

63 Los lanzallamas, p. 34.

64 Ibid., p. 187.

65 Ibid, p. 53.

60 Los siete locos, p. 346. 
hilo que lo mantenía ligado a Dios". ${ }^{67}$ Una vez roto ese hilo, por medio del pecado y del crimen que va a cometer mañana permitiendo el asesinato a sangre fría de Barsut, su próximo paso será mucho más fácil: "si supiera ahora lo fácil que va a ser morir. Como un juego"; "si ahora somos como dioses", le dice a Hipólita repitiendo la idea de Kirílov. Y cuando ésta le pregunta si tendrá el valor de matarse, Erdosain le replica: "Ya no hay coraje ni cobardía. Desde muy adentro tengo la sensación de que suicidarse es como irse a sacar una muela". ${ }^{68}$

Los crimenes que proyecta Erdosain (el asesinato de Barsut, la ten. tación de matar a Hipólita y el asesinato de la Bizca) son a su manera una protesta social. ¿Y qué es un crimen en comparación con los miles proyectados por la sociedad secreta? Lo más curioso es que de los tres crímenes proyectados, el que comete es el más inútil de todos. Al fin, Barsut es un caso de bravura y venganza, Hipólita es un caso de súbita inspiración que abandona inmediatamente, pero la Bizca, ¿qué obligación tenía de convivir con ella y luego de matarla? La pudo abandonar, pudo vivir con ella sin casarse, pudo casarse; sin embargo, en un rapto de verdadera locura, elige matarla de la misma forma que el rufián mató a su amante, reproduciendo el crimen que cree haber leído en los periódicos, pero que, por todos los indicios, debió de haber soñado. ${ }^{\text {ǵ }}$

Erdosain sabe que se va a matar; es la única cosa que sabe con seguridad. Después de interrogarse sobre el sentido de la vida, decide, "es mejor acabar", y acaricia el revólver, lo examina, lo aprieta contra su pecho, pero todavía no quiere morir; es necesario que sufra más, que se rompa más, dice el narrador, y el protagonista confirma: "tengo. que cometer unos cuantos crímenes más". ¿Por qué? ¿Qué relación hay entre su deseo de matar y'el suicidio? Erdosain estratégicamente se hace acorralar por circunstancias que no le permitan flaquear. Una vez cometido el crimen, Erdosain está listo para dar el salto final. Como el héroe de Les caves du Vatican, Erdosain no sabe a ciencia cierta para qué mata. Por angustia, pero el crimen no alivia su angustia; al contrario, la precipita, y en esto se acerca a Dostoievski. Es como si el protagonista quisiera sacar fuerza de sus crímenes para poder llegar al final. Esta certidumbre de su muerte va creciendo con su angustia, y se alivia sólo cuando piensa que de cùalquier modo, se matará. El suicidio, pues, es la única solución que el protagonista conscientemente se ha buscado, aunque de una manera obligada (por aquello de que la

\footnotetext{
si rbid., p. 347.

68 Ibid, p. 346.

69 No es fácil separar las alucinaciones del protagonista de la realidad.
} 
carne es flaca y el espíritu fuerte). No son muchas las alternativas que le quedan. Sabe que es un asesino buscado por la policía, ya no tiene tiempo para huir de la ciudad ni puede quedarse en ella. Nótese, además, lo simbólico de su muerte. Toma el tren de Moreno (al oeste de Buenos Aires), es decir, donde declina èl sol; el tren mismo es un símbolo de viaje que él siempre había soñado hacer; las once de la noche, símbolo de las tinieblas de su existencia; se dispara en el pecho, no en la cabeza, significando el verdadero lugar de sus sufrimientos, el corazón.

El pensamiento del suicidio persigue también a los otros personajes. Ya mencionamos cómo hasta el hombre fuette, el Astrólogo, pensó en matarse. Otros no solamente lo piensan sino que lo intentan de veras. Así, Haffner, el Rufián Melancólico, "una tarde, sin decir palabra, sin tocar uno de los tres mil pesos que había en la mesa de luz, después de meditar algunos minutos en la verdad que había descubierto "la vida no tiene objeto' se disparó un tịo al corazón, pero el proyectil, al tropezar con una costilla, se desvió". ${ }^{70}$ Nótese que no es el primer caso de suicidios malogrados en Arlt. Silvio antes e Hipólita (la prostituta bíblica) después. El caso Haffner, sin embargo, confirma una vez más la teoría arltiana, de que una vida sin "objeto" aun con dinero y todos sus beneficios, es insoportable. Hipólita, según su marido Ergueta, estaba tan desesperada después de su séptimo aborto que fue a tirarse desde el cuarto piso. $Y$ si no lo hizo, según la interpretación bíblica de Ergueta, fue porque se le apareció Jesús. Este episodio no encaja en el carácter de Hipólita, frío y calculador, peto sí es muy verosímil en el oficio de prostituta. Una de éstas, al servicio de Haffner, también se suicida. Hipólita presencia desde el agujero de su cuarto el atentado contra su vida de un viejo que al fin no tiene valor para llevarlo a cabo, lo que hace decidirla a unirse a los proyectos del Astrólogo de la destrucción de la ciudad. La muette en Arlt es compasiva, como lo confiesa Hipólita sinceramente al ver la indecisión del viejo que no tiene fuerzas para matarse: "Sufriria menos por él si se hubiera matado", piensa ${ }^{71}$

Resumiendo, la evasión de la ciudad, la búsqueda de un objeto en la vida, y la falta de un sentido en la vida son los temas que no sólo

70 Los lanzallamas, p. 135,

71 lobid., p. 97. 
unen las tres novelas aquí estudiadas, sino que dan a su autor una categoría universal. Es verdad que a través de Silvio Astier, Remo Etdosain y Estanislao Balder, Arlt transmite su propia angustia, buscando por medio de sus protagonistas - como él mismo lo había confesadouna respuesta a sus deseos de felicidad. Sin embargo, como se trata de problemas universales, de lo particular nos elevamos a lo general. De las tres soluciones posibles para sus personajes - la fuga de la ciudad al campo, la destrucción de la ciudad por medio de gases y ametralladoras y el suicidio- Arlt no elige ninguna personalmente. Es más fácil resolver los problemas de la humanidad por medio de la ficción que llevarlos a cabo en la realidad. Además, novelar fue su otra solución, la cuarta, la de soñar. Su acierto máximo fue el haber descrito el triste destino que le aguarda al hombre en la ciudad. Su solución, romántica y anarquista, loca y desesperada, difícilmente puede llamarse solución. La verdad es que Buenos Aires ha seguido creciendo, y hoy tiene cuatro veces más habitantes que en su tiempo, sin que los problemas señalados entonces hayan perdido su vigencia. Al contrario, los novelistas de las siguientes generaciones han continuado describiendo los mismos problemas urbanos, cada vez más complicados, ya señalados por Arlt, cada uno a su manera, buscando un sentido a la vida, que cada vez parece tenerlo menos

Al describir al hombre urbano de su época (1930) y de su ciudad, Arlt no sólo ha dejado un documento importante sobre el hombre de Buenos Aires (como Martínez Estrada y Scalabrini Ortiz en sus ensayos), sino que trasciende su tiempo y su espacio, remontándose al problema universal que confrontan muchos hombres de nuestro tiempo. Porque en todas las cindades del mundo, observa un personaje de Arlt, ocurre el mismo fenómeno, en todas las ciudades del mundo los hombres viven hacinados, mecanizados, alienados y sin sentido. Los valores tradicionales han sido ridiculizados y reemplazados por el culto de la máquina, los sentimientos disminuidos, el alma encadenada y el cuerpo profanado. Una vida así no tiene sentido y si para hacérselo entender hay que destruir a la humanidad, bien aniquilada estará, dice el Astrólogo, porque la vida del hombre no tiene ningún valor.

Arlt no es ni mucho menos, un caso único o aislado. Muchos escritores le precedieron en su preocupación (Baroja, Cervantes, Dostoievski, Gide, Hawthorne, Melville, Poe, Unamuno, etc.), otros son contemporáneos suyos (Camus, Leopoldo Marechal, Santayana, etc.), 
otros más, siguen sus pasos, como Juan Carlos Onetti y Julio Cortázar. El estudio de estos escritores arroja mucha luz sobre la angustia de nuestro tiempo y el fin "mesiánico" que persiguen, que no es otro que la regeneración del hombre total.

\section{Stasys Gostautas}

Wellesley College 